\title{
The study of design on the urban track transportation vibration prevention: floating slab track in the bored tunnel at Taipei
}

\author{
Sy. Chang ${ }^{1}$, K. Y. Chang ${ }^{2}$, K. H. Cheng ${ }^{3}$ \& R. J. T. Chen ${ }^{4}$ \\ ${ }^{I}$ China Engineering Consultants, Inc. Taipei, Taiwan, R.O.C. \\ ${ }^{2}$ Technology Dept of Civil Engineering, National Taipei University, \\ Taipei, Taiwan, R.O.C. \\ ${ }^{3}$ Central District Project Office of DORTS, TCG, Taiwan, R.O.C. \\ ${ }^{4}$ Special Advisor of Bureau of HSR, MOTC, Taiwan, R.O.C.
}

\begin{abstract}
Population concentration and the resulting traffic jams are a common phenomenon in modern society. Such problems are getting worse as time goes on. Although the highway area increases every year, traffic jams still can't be solved effectively. So the popularity of land transportation is decreasing in favour of track transportation. Track transportation has many advantages, but the noise and vibration induced from the wheel/rail contact are sensitive to the neighboring residents along the track route.

There are many complaints about noise and vibration from the residents along the Taipei MRT (TRTS) line where the TRTS tunnel is underneath the building, so TRTS decided to use one of best solutions to vibration prevention available to the track engineer - Floating Slab Track (FST).

In this paper, the overall issues of the FST based on consideration of the local area in the design stage were studied, including the mode of structure analysis, the vibration isolating component, material, localized geotechnical parameters, rail fastener, elastic coefficient, etc. We hope this paper can share our practical experience and the results of the study for the vibration prevention in track at the urban transportation for environmental pollution prevention, to other railway systems or to academia in the environment field and railway field.

Keywords : vibration, localize, Floating Slab Track, vibration prevention, elastic coefficient.
\end{abstract}




\section{Foreword}

Population concentration and the resulting traffics jam are a common phenomenon in modern Taiwanese society. Such problems are getting worse as time goes by. Although the roadway area increases every year, traffic jams still can't be solved effectively. So the popularity of land transportation is decreasing in favour of track transportation. They have a many complains about the noise and the vibration from the Taipei MRT (TRTS) operation at the Chungho line, the noise and vibration problems produced by the train/track interface, due to the wheel/track contact, which generates friction and impact. This vibration effectively propagates through the ground to the neighbouring buildings along the track route, which will transmit noise and damage to sensitive equipment. The modern railway will solve noise and vibration problems by track/ EMU/ geology/ structure. The track has elastic rail fasteners, elastic rail boots, elastic trackbed (floating slab, LVT, tie with elastic boots). The Xinzhung/Luzhou new line has room to pass under the existing buildings on the line and will use the floating slab track to solve the vibration problems. This paper will provide some suggestions for the design details of the floating slab to be used in Taiwan area, and provide references and data for the design and selection of the floating slab in this area.

\section{The source of track vibration}

The vibration of track was cause by the following reasons when the railroad train is running on the track (see the figure 1).

(1) Wheel roughness

They have difference maintenance values of wheel truing in different track transportation systems, so the track design has to following the maintenance figure of the wheel truing of the Taipei Rapid Transit Company.

(2) Rail corrugation

The characteristic of the rail corrugation / the rail wear wave-pattern will depend on the local track transportation system, choosing the wrong factor will cause a more serious vibration problem, so the track design has to follow the maintenance figure of the rail grinding of the Taipei Rapid Transit Company.

(3) Wheel and rail grinding abrasion metal chipping.

(4) Discontinuous rail

Taipei Rapid Transit system uses the non-rail expansion join of the continuous welding rail system, which has less vibration problems. The rail insulated joint shall away from the gap between two floating slab, in case of the abnormal loading in the rail insulated joint caused by the different deformation between two track slabs.

Roughness of the track supporting structure 
The Taipei Rapid Transit system was constructed using a concrete track plinth on the mainline and concrete track slab in special track areas, so it should have high accuracy of track construction, it should consider the uniform of longitudinal stiffness in the transition section of floating slab connected to the main line track, the re-evaluation of the elastic coefficient of rail fastener base plate, and transition design of the floating slab.

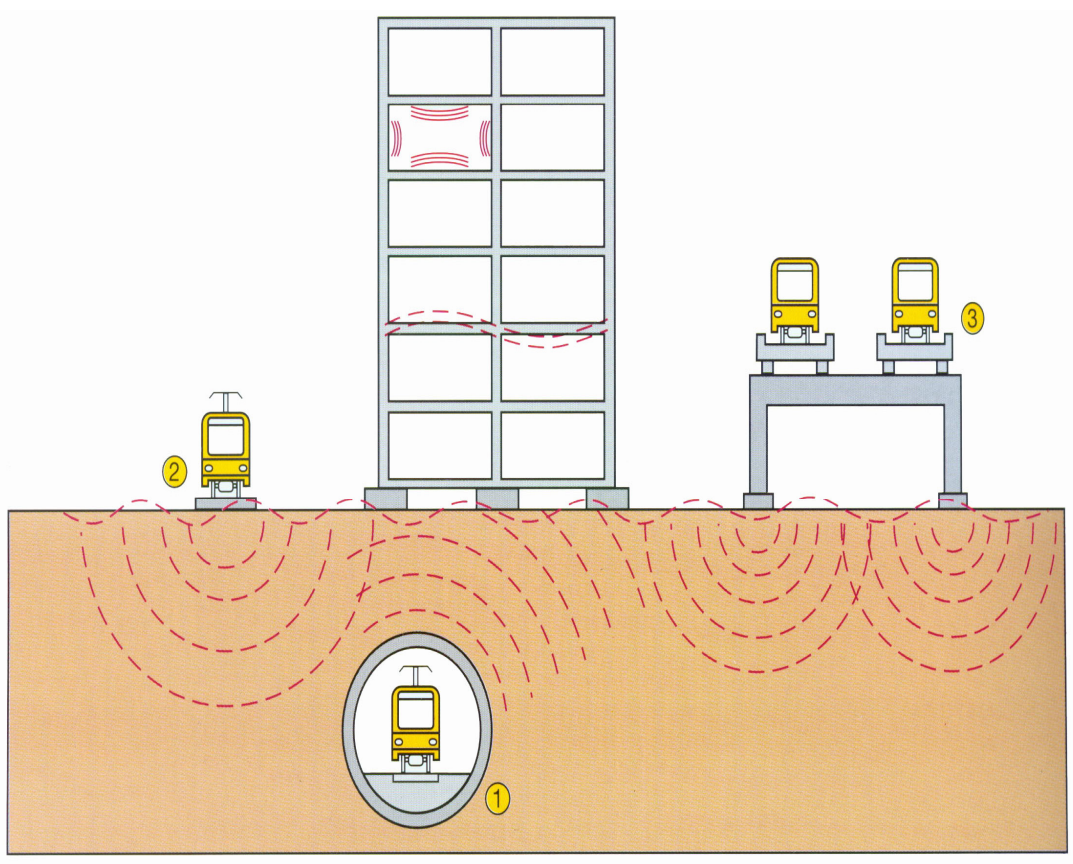

Figure 1: $\quad$ Track ground-borne Vibration Propagation Route (GERB).

The above mention reasons will cause the track vibration, and this source of the vibration will use the following way to the ground.

(1) Track system

The track system was including the rail and rail fastener and concrete trackbed.

(2) Tunnel structure

The tunnel structure types have cut and cover and bored tunnel.

(3) Geotechnical conditions

The soil type and the ground born-vibration deduction factor are the main key issues of the floating slab design, so the track contractor should have a site investigation and measurement along the line to define the ground born vibration deduction factor. 


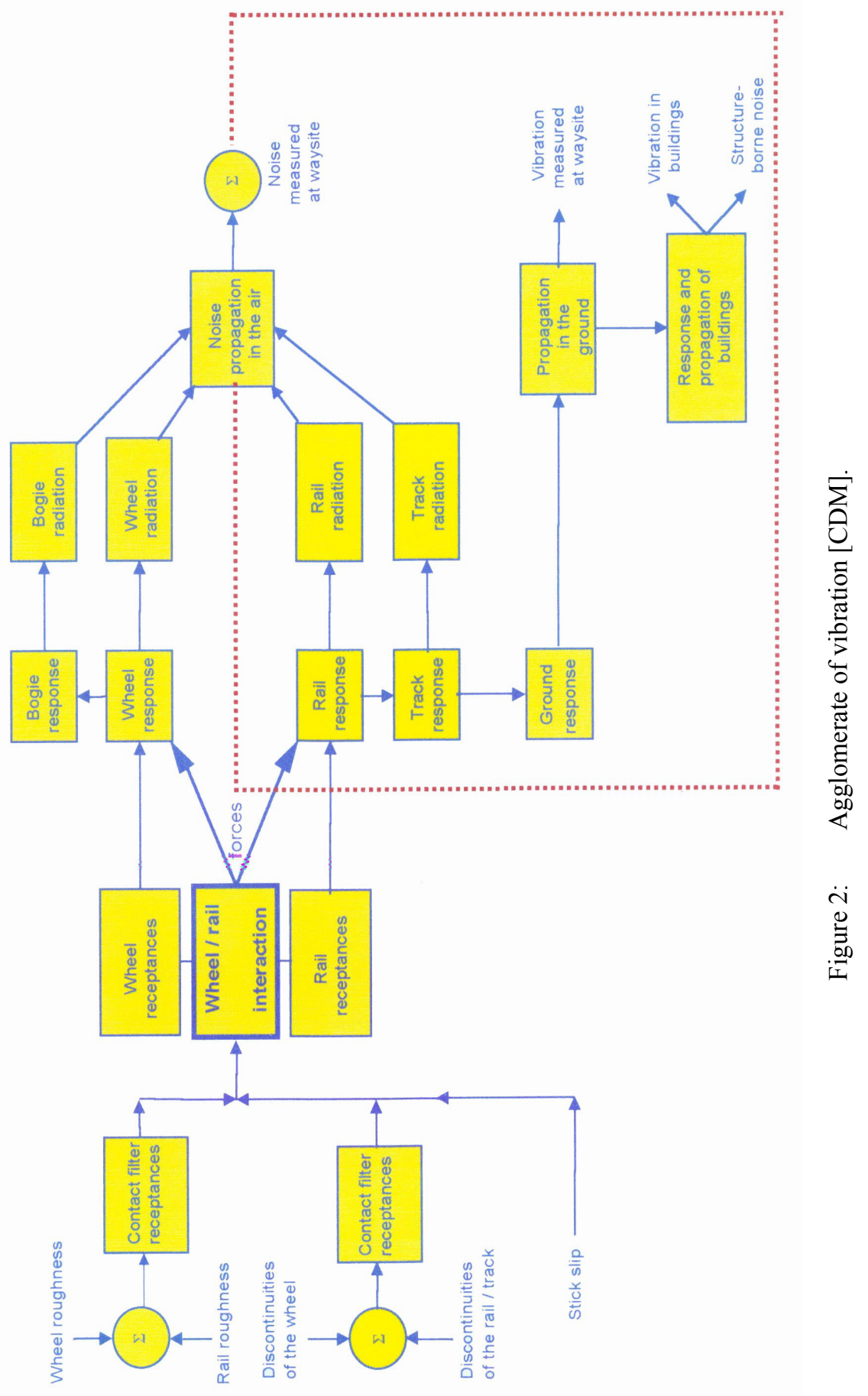


(4) The resident structure foundation inside the structure

Different types of structure will directly affect the vibration measuring value inside the adjacent buildings along the line; it should be investigated carefully (the investigation should include structural stiffness, resonance frequency, number of floors, etc.) of the adjacent building along the line. These kinds of vibration maybe affect the living quality of resident and some equipment operation, but it would not to damage the adjacent building along the line.

\section{The vibration reduction of the floating slab}

The floating slab under the track and the EMU was the source of vibration of track transportation system. The floating slab design was based on the SpringMass System. The floating slab design needs to go through overall systematic consideration. The design parameters that need to be considered include: the mass and stiffness values of each components of the train, mass and elastic coefficient / damping ratio values of each track component, structural types and geotechnical parameters, the wheel / rail interface during contact and other practical operational considerations.

The floating slab used a concrete track slab with an elastic support to provide vibration attenuation and energy absorption, and the heavier the mass of track slab will have a better result. However, a larger track slab will need more room in the civil structure, increasing the initial cost of the civil structure and at the same time increase the initial cost of the floating slab. Also the mass of the track slab must be suitable for the elastic support: the softer the support the better the vibration attenuation, but a soft support will lead to rail deformation that will make the track unstable, so an appropriate elastic coefficient should be selected.

Both track slab and isolating / deduction of vibration system should have a overall consideration of the natural frequency of the floating slab, to avoid resonance between the car body and track and civil structure and soil propagation and adjacent buildings (the soil propagation frequency rang was within $25-150 \mathrm{~Hz}$, each parts of car body was within $1-60 \mathrm{~Hz}$ ).

To avoid damage to the floating slab as trains run on the track (natural frequencies in the range of $5-150 \mathrm{~Hz}$ ), one has to perform a static and dynamic analysis in the track design: the vibration analysis of the track has a one car length vibration model (see figure 3), weight of car body, Mc, primary suspension system elastic coefficient, Ks1, damping ratio, Cs1, mass of bogie, $\mathrm{Mt}$, secondary suspension system elastic coefficient, Ks2, damping ratio, Cs2, wheel load, Mw, and dynamic loading transfer to the track P1(t), P2(t), P3(t), $\mathrm{P} 4(\mathrm{t})$.

The early stage of conceptual design uses a simple model to calculate the natural frequency of each element of the track structure away from the natural frequency of car and soil.

We have studied the Taipei mass rapid transit Xinzhung/Luzhou line and perform a simple model calculation, and gained the following results 
Nature frequency Wn $(\mathrm{Hz})$

Case 1

Rail base plate mass $=2144 \mathrm{~kg}$

elastic coefficient $=25 \mathrm{kN} / \mathrm{mm} * 8=200 \mathrm{kN} / \mathrm{mm}$

bearing pad / floating slab mass $=5163 \mathrm{~kg}$

elastic coefficient $=8 \mathrm{kN} / \mathrm{mm} * 8=64 \mathrm{kN} / \mathrm{mm}$

Case 2

Rail base plate mass $=2900 \mathrm{~kg}$

elastic coefficient $=25 \mathrm{kN} / \mathrm{mm}^{*} 20=500 \mathrm{kN} / \mathrm{mm}$

bearing pad / floating slab mass $=26710 \mathrm{~kg}$

elastic coefficient $=8 \mathrm{kN} / \mathrm{mm} * 20=160 \mathrm{kN} / \mathrm{mm}$

Case 3

Rail base plate Mass $=2013 \mathrm{~kg}$

elastic coefficient $=25 \mathrm{kN} / \mathrm{mm} * 8=200 \mathrm{kN} / \mathrm{mm}$

Bearing pad / floating slab Mass $=5032 \mathrm{~kg}$

elastic coefficient $=10 \mathrm{kN} / \mathrm{mm} * 8=80 \mathrm{kN} / \mathrm{mm}$

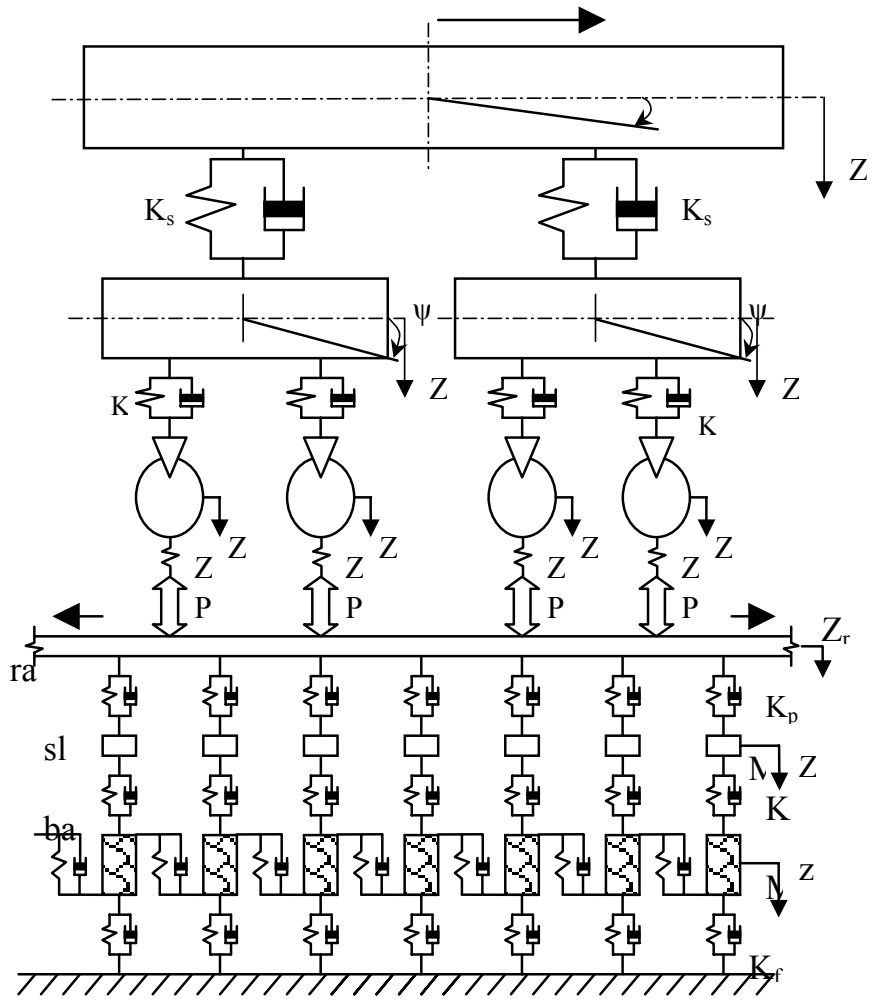

Figure 3: Vertical integration system of track. 
Table 1.

\begin{tabular}{|c|c|c|c|}
\hline & Mass (kg) & $\begin{array}{c}\text { Elastic } \\
\text { coefficient } \\
(\mathrm{kN} / \mathrm{mm})\end{array}$ & $\begin{array}{c}\text { Natural } \\
\text { frequency } \\
(\mathrm{Hz})\end{array}$ \\
\hline $\begin{array}{c}\text { Bearing pad / FST } \\
(\mathrm{M} 1, \mathrm{~K} 1)\end{array}$ & 5163 & 64 & 15.052 \\
\hline $\begin{array}{c}\text { Rail base plate } \\
(\mathrm{M} 2, \mathrm{~K} 2)\end{array}$ & 2144 & 200 & 58.853 \\
\hline $\begin{array}{c}\text { Primary suspension system } \\
(\mathrm{M} 3, \mathrm{~K} 3)\end{array}$ & 5847 & 2.67 & 3.692 \\
\hline $\begin{array}{c}\text { Secondary suspension system } \\
(\mathrm{M} 4, \mathrm{~K} 4)\end{array}$ & 12250 & 0.57 & 0.972 \\
\hline
\end{tabular}

Table 2.

\begin{tabular}{|c|c|c|c|}
\hline & Mass (kg) & $\begin{array}{c}\text { Elastic } \\
\text { coefficient } \\
(\mathrm{kN} / \mathrm{mm})\end{array}$ & $\begin{array}{c}\text { Natural } \\
\text { frequency (Hz) }\end{array}$ \\
\hline $\begin{array}{c}\text { Bearing pad / FST } \\
(\mathrm{M} 1, \mathrm{~K} 1)\end{array}$ & 26710 & 160 & 11.793 \\
\hline $\begin{array}{c}\text { Rail base plate } \\
(\mathrm{M} 2, \mathrm{~K} 2)\end{array}$ & 2900 & 500 & 69.841 \\
\hline $\begin{array}{c}\text { Primary suspension } \\
\text { system (M3, K3) }\end{array}$ & 5847 & 0.57 & 0.976 \\
\hline $\begin{array}{c}\text { Secondary suspension } \\
\text { system (M4, K4) }\end{array}$ & 12250 & & \\
\hline
\end{tabular}

Table 3.

\begin{tabular}{|c|c|c|c|}
\hline & $\begin{array}{c}\text { Mass } \\
(\mathrm{kg})\end{array}$ & $\begin{array}{c}\text { Elastic } \\
\text { coefficient } \\
(\mathrm{kN} / \mathrm{mm})\end{array}$ & $\begin{array}{c}\text { Natural frequency } \\
(\mathrm{Hz})\end{array}$ \\
\hline Bearing pad / FST & 5,032 & 80 & 17.014 \\
$(\mathrm{M} 1, \mathrm{~K} 1)$ & 2013 & 200 & 60.587 \\
\hline $\begin{array}{c}\text { Rail base plate (M2, K2) } \\
\text { Primary suspension } \\
\text { system (M3, K3) }\end{array}$ & 5847 & 2.67 & 0.973 \\
\hline $\begin{array}{c}\text { Secondary suspension } \\
\text { system (M4, K4) }\end{array}$ & 12250 & 0.57 & \\
\hline
\end{tabular}




\section{Conclusions and recommendations}

For the study of floating slabs in Taiwan we know that a full picture analysis in the design and construction stage has to be produced, but the different track transportation systems have different characteristics, and different problems that need to be solved, so we summarise some recommendations as follows:

(1) It has to measure the natural frequency of the car body.

(2) The optimization design of the floating slab should follow the results from track and structure analysis.

(3) The detail investigation of types of adjacent buildings and detailed analysis of the structure characteristics to avoid vibrational resonance.

(4) It should carefully analyse the impact factor of ground-borne vibration, especially for the soil: this information should be established by the site measurement and the construction data.

(5) To cooperate with the maintenance plan of the operation unit that will get the optimal design of floating slab.

For high speed railways, mass rapid transit system, traditional railway systems or light rail system the floating slab is still be the best and most efficacious solution, but it construction cost will be 3 to 10 times the non-ballasted track, so most systems will re-evaluate its necessity before using it, and its real vibration deduction was depend on the accurate analysis, and adequate design and construction. This paper collected local design factors for the future development of a Taiwanese floating-slab track, and we hope this paper can serve as a useful tool for the future use of floating slab tracks in Taiwan and share our experience worldwide.

\section{References}

[1] Kuo H. Cheng et al, The Study on The Floating Slab for Reduce The Noise and Vibration, 2002 World Metro Symposium, Taipei-Taipei City Government, 25-27 April 2002.

[2] Sy Chang et al, Trackwork Innovation-Non-Ballasted Track In Taiwan, Eighth International Conference on Computers in Railways -COMPRAIL VIII, Wessex Institute of Technology, 12-14 June 2002.

[3] The study on the Floating Slab - an alternative to reduce the noise and vibration level of non-ballast track. 